Research Article

\title{
Design and Performance of Ultrathin Overlay Epoxy-Rubber Concrete
}

\author{
Qi Huang ${ }^{1}$ and Fei Chen $\mathbb{1 D}^{2}$ \\ ${ }^{1}$ North China University of Water Resources and Electric Power, Zhengzhou 450045, China \\ ${ }^{2}$ Department of Highway Research Center, Research Institute of Highway Ministry of Transport, Beijing 10000, China
}

Correspondence should be addressed to Fei Chen; f.chen@rioh.cn

Received 26 July 2021; Accepted 14 September 2021; Published 24 September 2021

Academic Editor: Francesco Colangelo

Copyright ( 2021 Qi Huang and Fei Chen. This is an open access article distributed under the Creative Commons Attribution License, which permits unrestricted use, distribution, and reproduction in any medium, provided the original work is properly cited.

\begin{abstract}
Epoxy-rubber concrete has a big potential to be used for pavement overlays, but there is currently no appropriate epoxy-rubber concrete design method and process. To explore the reasonable mix design process of epoxy-rubber concrete, the ultrathin overlay aggregate gradation and epoxy resin binder with high toughness and durability were selected to carry out the design process investigation of epoxy-rubber concrete. The performance of epoxy-rubber concrete was characterized by vibration compaction, repeated load CBR, porosity, Fort Kentucky, uniaxial compression, bending, rutting, antiskid performance, and noise-reduction performance test. Firstly, the optimum range of the rubber powder replacement rate was determined based on the porosity and deformation characteristics of the aggregate mixture. Then, the amount of epoxy resin binder was further determined based on the porosity and antistripping performance of the epoxy-rubber concrete. Finally, the mechanical properties, road performance, and functions of epoxy-rubber concrete were comprehensively considered to determine the optimum rubber power replacement rate obtaining the composition design of epoxy-rubber concrete. The results showed that adding rubber powder decreased the elastic modulus and plastic deformation of the mineral structure, enhancing the suitability of the mixture for flexible road pavements. However, when the replacement rate increased to a specific range, the rubber particles significantly interfered with the mineral material, worsening the stability of the structure. Therefore, it was preliminarily determined that the reasonable replacement rate of rubber powder was 30-50\%. The ultrathin overlay epoxy-rubber concrete exhibited excellent antistripping performance, and its porosity increased with the epoxy resin dosage. The optimum epoxy content was $6.5 \%$ at $4.17 \%$ porosity. Within the preliminarily determined replacement rate range of rubber particles, as the replacement rate increased, the flexibility, high-temperature stability, antiskid performance, and shock and noise resistance of the mixture increased, but the compressive and flexural tensile strength values decreased. The integrated properties of the ultrathin overlay epoxy-rubber concrete indicated that the best replacement rate of rubber powder was $45 \%$. In this paper, the replacement rate range of the rubber powder was initially determined based on the gradation composition of the mixture, which avoids blind determination of the replacement rate. And the composition of the concrete was obtained comprehensively by the performance and function of the epoxy-rubber concrete, which is reasonable and reliable. The epoxy-rubber concrete design method proposed in this paper can promote the application the epoxy-rubber concrete in pavement overlay engineering.
\end{abstract}

\section{Introduction}

The ultrathin-surface layer can effectively reduce the fatigue and temperature cracking of asphalt pavements, and it exhibits high flatness, strong skid resistance, and efficient noise reduction [1-3].
A research focus in resource utilization and environmental protection is the efficient treatment of waste tires. The proper recycling and reuse of waste tires can preserve natural resources and generate significant social and economic benefits. Rubber granules are obtained from recycled waste tires containing natural rubber and carbon black, and 
their use in road construction can improve road performance and durability $[4,5]$. Currently, the crushing of waste tires into rubber powder as a pavement material is a widely accepted treatment technique. Rubber-powder modified cement-based concrete [6,7], asphalt-based concrete $[8,9]$, and polymer concrete [10] have been extensively researched and applied. Epoxy resin concrete is a type of polymer concrete that exhibits excellent characteristics, such as high strength, short curing time, improved durability, and freezing-thawing resistance $[11,12]$. Epoxy resin concrete is used in bridge deck paving, rapid pavement repair, color pavements, and special-use pavements [10,13-15]. Polymer concrete has good durability, and under good binder selection, it has potentials for high-temperature stability and low-temperature crack resistance better than asphalt concrete [16]. Polymer concrete can bond well with the original pavement structure, avoiding a series of diseases caused by insufficient interlayer bonding [17]. At the same time, polymer concrete does not need to be heated during use, which saves energy and does not cause air pollution compared with hot mix asphalt concrete regardless of the season and can be opened to traffic quickly after its construction [16]. However, problems are encountered when using epoxy resin concrete, limiting its wide application in road construction and maintenance. The thermal conductivity of epoxy resin concrete is different from that of traditional concrete; therefore, excessive temperature difference may affect its performance. The toughness of epoxy resin is low, which adversely affects its low-temperature performance, but the toughness of ordinary epoxy concrete can be improved by adding an elastomer phase [16]. The epoxy resin modulus is close to that of rubber particles, and the epoxy resin exhibits good adhesion. Modified epoxy resin concrete containing rubber particles can exhibit improved flexural performance, crack resistance, and impact resistance. Therefore, epoxy concrete containing plastics and waste tire rubber may possess improved toughness and durability.

However, the application of rubber particles in resin concrete is an emerging research direction. A few related studies have been conducted, mainly focusing on the effect of rubber particles on resin concrete properties and the concrete performance at different temperatures. Shen et al. [17] investigated the mechanical properties of polymermodified porous concrete containing rubber particles and found that rubber improved the energy absorption capacity, ductility, wear resistance, and impact resistance of the concrete. Diaconescu et al. [18] investigated the effect of rubber particle content on the properties of epoxy resin concrete by using experimental tests and simulations and predicted the performance of polymer concrete containing rubber particles. In the Diaconescu study, optimum mechanical properties were the objective of the material design, on the basis of which the admixture of resin and rubber powder was determined and the resulting rubber-epoxy concrete was suitable for the preparation of mechanical components. Roh et al. [19] developed two methods of adding liquid rubber admixture and waste rubber tire particles to epoxy resin concrete to repair the incompatibility in cement concrete runway with epoxy resin concrete at different temperatures. They observed that adding waste rubber tire particles has a better effect than liquid rubber on the compatibility of repaired road surfaces under temperature changes. Wang et al. [20] evaluated the mechanical and thermal properties of rubber-modified epoxy concrete through laboratory tests. The results showed that rubber particles could improve the mechanical properties of epoxy concrete materials and reduce the thermal conductivity of the mixture. Therefore, recycling solid waste rubber tires in epoxy resin-based polymer concrete is an eco-friendly approach for producing polymer concrete with good mechanical properties and durability.

In summary, epoxy concrete exhibits high tensile strength, good bonding strength, excellent durability, and rapid curing speed. The addition of a suitable amount of waste rubber powder as a partial replacement of the fine aggregate can increase the toughness and resistance of concrete. Cracking and noise reduction suggest the significant potential of epoxy-rubber concrete in road pavement, but the lack of a standardized design process limits the research and application of epoxy-rubber concrete. In this study, the structural deformation, mechanical properties, road performance, and other indicators of ultrathin overlay epoxy-rubber mixture were used as the preferred indicators to determine the epoxy resin content and the replacement amount of rubber particles in the ultrathin overlay epoxyrubber concrete. This can broaden the application of epoxy resin concrete in highway engineering and provide a new method of recycling waste tires.

\section{Experimental Program}

2.1. Materials. The epoxy-rubber concrete used in this study consisted of an epoxy resin binder, waste rubber powder, and aggregates.

2.1.1. Epoxy Resin Binder. The epoxy resin binder was composed of the following four materials in a designed proportion: (1) resin (E51 epoxy resin, a bisphenol A-type liquid epoxy resin with an epoxy value of $0.48-0.54) ;(2)$ toughening agent, which was polypropylene glycol diglycidyl ether (PPGDGE), with an epoxy value of 0.32 ; (3) curing agent, which was polyamide 650 , with an amine value of 140 and a hydrogen equivalent of 200; (4) cesium dioxide of diameters of 5-20 microns. The ratio of the four materials used for the epoxy resin binder is listed in Table 1 .

2.1.2. Crumb Rubber. The rubber powder was obtained through a mechanical milling process. The powder obtained from the waste radial rubber tires was ground into eight mesh sizes. The particle size distribution range was $0-2.36 \mathrm{~mm}$, and the average apparent relative density was $1.24 \mathrm{~cm}^{3} / \mathrm{g}$. The screening results are shown in Figure 1 .

2.1.3. Aggregates. Crushed granite stone, basalt rock chips, and ground limestone ore powder were used as the coarse aggregate, fine aggregate, and filler, respectively. The 
TABle 1: Proportion of binder.

\begin{tabular}{lccc}
\hline E51 epoxy resin & Toughening agent & Curing agent & $\begin{array}{c}\text { Cesium } \\
\text { dioxide }\end{array}$ \\
\hline 100 & 45 & 95 & 0.3 \\
\hline
\end{tabular}

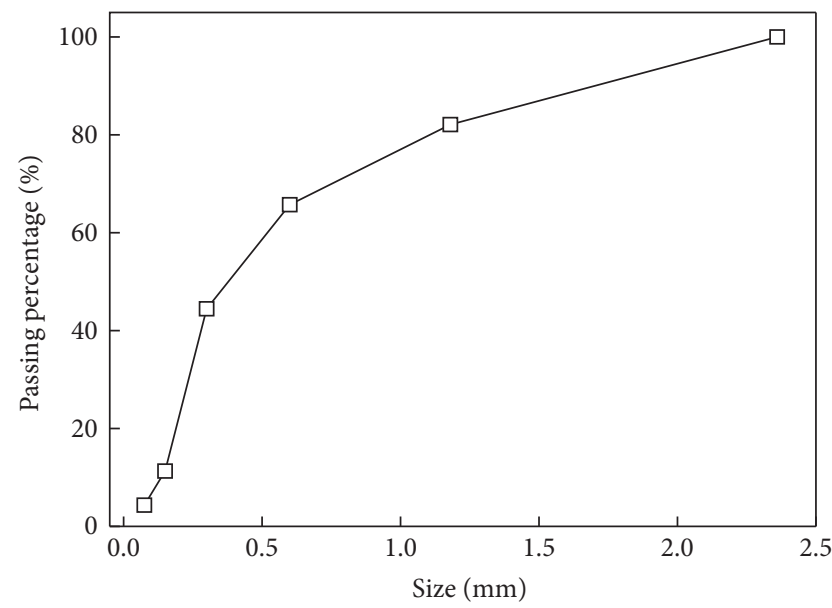

FIgURe 1: Particle size distribution of rubber powder.

aggregate gradation was selected according to the requirements of the "Technical Specification for Construction of Ultrathin Road Surfaces" (DB11/T1590-2018) Type III. The median gradation of the ultrathin overlay asphalt mixture and the gradation and density of the minerals are listed in Table 2 .

\subsection{Mix Design Process}

2.2.1. Preliminary Design of Crumb Rubber Dosage. The rubber powder was used to replace an equal volume of the fine aggregate at replacement rates of $0,10,30,50,70$, and $90 \%$. However, the rubber powder cannot be "fully" subjected to blows from the compaction hammer during compaction, unlike other mineral materials, thus, interfering with the aggregate structure. Therefore, the analysis of the tapped porosities of mixtures with different compositions did not influence the aggregate structure, and repeated load California bearing ratio (CBR) tests were performed to analyze the deformation of the mixture. Thus, a suitable range of rubber powder replacement rate could be determined.

2.2.2. Design of Optimum Epoxy Resin Binder Content. A specific amount of rubber was used to prepare the mixtures containing different epoxy resin contents $(5.5,6.0,6.5,7.0$, $7.5 \%)$ to determine the optimum epoxy resin content via porosity and Fort Kentucky tests.

2.2.3. Final Design of Crumb Rubber Content. Based on the test results presented in Section 2.2.1, the replacement rate range of the rubber powder was determined, and five replacement rates $(30,35,40,45$, and $50 \%)$ were used. The rubber was combined with different amounts of epoxy resin determined in the previous step. The powder content effects on the compressive strength, low-temperature bending, rutting, antiskid, and noise-reduction properties of ultrathin overlay epoxy-rubber concrete were evaluated. In addition, the mix ratio of ultrathin overlay epoxy-rubber concrete was determined.

\subsection{Testing Method}

2.3.1. Vibration Compaction Test. A vibration sensor was used for the vibration compaction tests. The prepared mineral material was thoroughly mixed and divided into three layers. The top surface of the compacted sample was equal to or slightly lower than $1 / 3$ of the cylinder height each time. After the first layer was loaded, the machine was vibrated and compacted at a frequency of $25 \mathrm{~Hz}$ and vibrated for $6 \mathrm{~min}$. Next, the vibrator was raised to load, vibrate, and compact the second layer of samples, and subsequently, the third layer was subjected to similar procedures. After the three-layer test was completed, the height of each test sample was calculated, and the tap density $\rho_{V}$ of the sample mineral material was calculated based on the feeding quality.

The volumetric flask method was used to analyze the gross bulk densities of different mineral material grades, and the synthetic gross bulk densities of the mineral materials were computed using the following equation:

$$
\rho_{S}=\sum\left(\rho_{i} \times P_{i}\right)
$$

where $\rho_{S}$ is the synthetic gross bulk density of a mineral material $\left(\mathrm{g} / \mathrm{cm}^{3}\right), \rho_{i}$ is the gross bulk density of the $i^{\text {th }}$ grade mineral material $\left(\mathrm{g} / \mathrm{cm}^{3}\right)$, and $P_{i}$ is the proportion of the $i^{\text {th }}$ grade mineral material in the mixture (\%).

The tap density of the mineral was determined and combined with the synthetic gross bulk density of the mineral, and the tap clearance ratio of the mineral was calculated using the following equation:

$$
V C A_{V}=\left(1-\frac{\rho_{V}}{\rho_{S}}\right)
$$

where $V C A_{V}$ is the tap clearance rate of mineral materials (\%) and $\rho_{V}$ is the tap density of a mineral material $\left(\mathrm{g} / \mathrm{cm}^{3}\right)$.

2.3.2. Repeated Load CBR Test. A MTS testing machine was used to perform repeated load CBR tests. The cylindrical specimen size was $\Phi 152 \mathrm{~mm} \times 100 \mathrm{~mm}$. The load was a halfsine wave dynamic, the maximum load sine-wave value was $5 \mathrm{kN}$ (equivalent to $2.55 \mathrm{MPa}$ stress), and the loading frequency was $0.1 \mathrm{~Hz}$ under 200 loading cycles.

2.3.3. Porosity Test. The porosity test was conducted using the method described by Milena [21]. First, the test piece size was measured, the test piece volume $V$ was calculated, and the drying mass $M_{\mathrm{d}}$ of the test piece was then weighed. Subsequently, the test piece was immersed in water for $24 \mathrm{~h}$ to assess its quality in water $M_{\mathrm{w}}$, and finally, the porosity of the specimen was obtained using the following equation: 
TABLE 2: Gradation and density values for different grain sizes.

\begin{tabular}{|c|c|c|c|c|c|c|c|c|c|c|}
\hline Mesh size $(\mathrm{mm})$ & 9.5 & 7.2 & 4.75 & 2.36 & 1.18 & 0.6 & 0.3 & 0.15 & 0.075 & Mineral powder \\
\hline Pass rate range $(\%)$ & $90-100$ & $56-68$ & $30-40$ & $23-32$ & $16-24$ & $11-19$ & $8-15$ & $6-12$ & $5-9$ & - \\
\hline Median $\mathrm{p}$ & 95 & 62 & 35 & 27.5 & 20 & 15 & 11.5 & 9 & 7 & - \\
\hline Gross volume relative density $\left(\mathrm{cm}^{3} / \mathrm{g}\right)$ & 2.779 & 2.769 & 2.767 & 2.871 & 2.900 & 2.900 & 2.895 & 2.897 & 2.881 & 2.701 \\
\hline Apparent relative density $\left(\mathrm{cm}^{3} / \mathrm{g}\right)$ & 2.805 & 2.793 & 2.793 & 2.905 & 2.900 & 2.900 & 2.895 & 2.897 & 2.881 & 2.701 \\
\hline
\end{tabular}

$$
\varphi=1-\frac{M_{d}-M_{w}}{\rho_{w} * V},
$$

where $\rho_{w}$ is the density of water.

2.3.4. Fort Kentucky Test. A standard Marshall test piece of $\Phi 101.6 \mathrm{~mm} \times 63.5 \mathrm{~mm}$ was submerged in a constant-temperature water bath at $20^{\circ} \mathrm{C}$ for $20 \mathrm{~h}$. The test piece was then placed in a Los Angeles testing machine and subjected to 300 revolutions at a speed of $32 \mathrm{rpm}$. The mass of the largest specimen remaining after flying was weighed, and the ratio of this mass to the mass of the Marshall specimen before flying was obtained. This ratio is defined as the dispersion loss amount.

2.3.5. Uniaxial Compression Test. A CMT5105 microcomputer-controlled electronic universal testing machine was used to perform uniaxial compression tests to determine the compressive strength of the ultrathin epoxy-rubber concrete. Rutting plates of $300 \mathrm{~mm} \times 300 \mathrm{~mm} \times 50 \mathrm{~mm}$ were fabricated using the wheel rolling method (T0703-2011). Prism asphalt mixture specimens of $40 \mathrm{~mm} \times 40 \mathrm{~mm} \times 80 \mathrm{~mm}$ were cut for uniaxial compression tests (T0714-1993). The curing temperature was $25^{\circ} \mathrm{C}$, and the loading rate was $50 \mathrm{~mm} / \mathrm{min}$.

2.3.6. Bending Test. A CMT5105 microcomputer-controlled electronic universal testing machine was used for the bending test to determine the flexural tensile strength and strain of ultrathin epoxy-rubber concrete. Plate specimens of $300 \mathrm{~mm} \times 300 \mathrm{~mm} \times 50 \mathrm{~mm}$ were fabricated using the wheel rolling method (T0703-2011). The specimens were cured in a box at $25^{\circ} \mathrm{C}$ for $24 \mathrm{~h}$ and then demolded and cut into beam specimens of $250 \mathrm{~mm} \times 30 \mathrm{~mm} \times 35 \mathrm{~mm}$. The curing temperature was $-10^{\circ} \mathrm{C}$, and the loading rate was $50 \mathrm{~mm} / \mathrm{min}$.

2.3.7. Rutting Test. Rutting tests were performed as per the test rules for asphalt and asphalt mixture in Highway Engineering (JTG E20-2011). The size of each specimen was $300 \mathrm{~mm} \times 300 \mathrm{~mm} \times 50 \mathrm{~mm}$, the test temperature was $60^{\circ} \mathrm{C}$, and the wheel pressure was $0.7 \mathrm{MPa}$.

2.3.8. Antiskid Performance Test. The fixed-point friction coefficient detection method was used to evaluate the antisliding performance of ultrathin epoxy-rubber concrete. The test principle is to allow the pendulum to fall from a specified height. The rubber sheet at the pendulum bottom slides over the surface of the specimen up to a specific distance, and the potential energy of gravity is transformed to work as the mechanical potential energy and overcome the antiskid friction of the road surface. The antiskid value was calculated and determined according to the principle of energy conservation. The test specimen was the $300 \mathrm{~mm} \times 300 \mathrm{~mm} \times 50 \mathrm{~mm}$ plate described in 2.3.7.

2.3.9. Noise Reduction Performance Test. The ultrathin overlay epoxy-rubber concrete was shaped into rut plates of $300 \mathrm{~mm} \times 300 \mathrm{~mm} \times 50 \mathrm{~mm}$, and vertical free-fall attenuation vibration tests on the two test pieces were performed. Radial 195/60R14 pull-back tires were selected, and the tire pressure was $250 \mathrm{kPa}$. During testing, the acceleration sensor was fixed on the test piece with epoxy resin, and the tire was allowed to freely and vertically fall $3 \mathrm{~cm}$ away from the test piece. The acceleration signal of the vibration attenuation process was received by the acceleration sensor fixed at each measurement point of the test piece.

\section{Results and Discussion}

\subsection{Effect of Rubber Powder Replacement Rate on Aggregate Structure and Deformation}

3.1.1. Effect on Porosity. As the replacement rate of rubber particles increased, the tapped porosity increased (Figure 2), indicating that the coarse aggregate skeleton gradually lost stability with the addition of rubber particles. The secant slope of the tapped porosity sharply increased when the rubber powder replacement rate exceeded $50 \%$. This sharp increase occurred because the rubber particles had already caused skeleton spreading, which reduced the strength of the mixture. The calculated values of the secant slope are listed in Table 3. The following inferences were drawn. When the replacement rate of rubber powder is between $0 \%$ and $50 \%$, the average increase rate of voidage is 0.033 . When the replacement rate of rubber powder increases from $50 \%$ to $70 \%$ and $90 \%$, the increase rate of voidage is 0.266 and 0.205 , respectively. Based on the above analysis, the tapped porosity increased when the rubber particle replacement rate was lower than $50 \%$, but this increase was small, which slightly influenced the overall stability of the skeleton. However, the rubber particles expanded the skeleton when the rubber powder replacement rate exceeded $50 \%$. The suitable replacement rate of the rubber particles for optimized gradation was $0-50 \%$ to ensure skeleton stability.

3.1.2. Effect on Modulus of Resilience. As the rubber powder replacement rate increased, the compressive resilience modulus of the mixture decreased gradually (Figure 3). When the replacement rate was lower than $50 \%$, the decrease was relatively slow. At a replacement rate of $50 \%$, the 


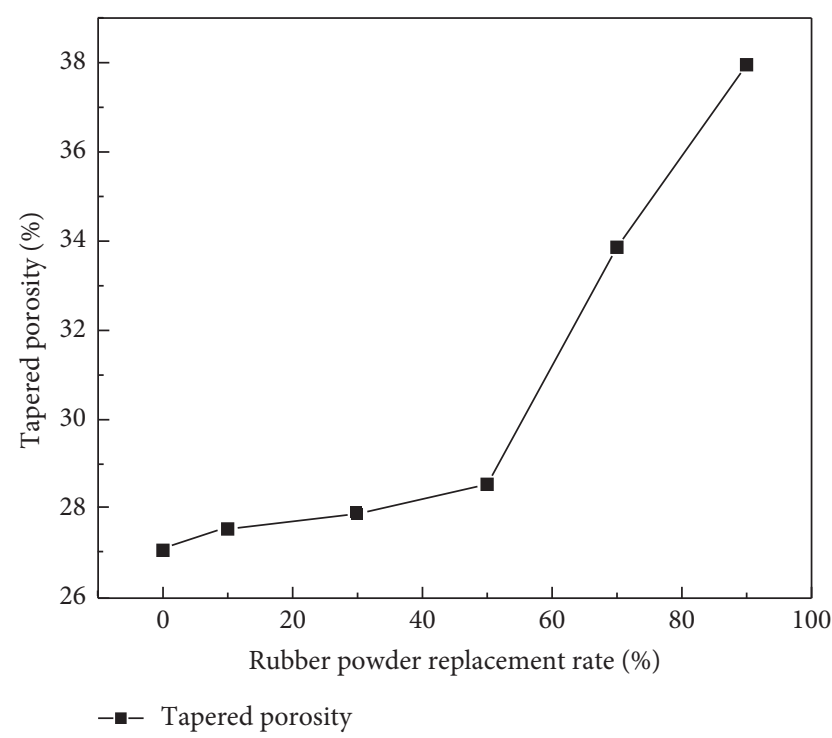

Figure 2: Relationship between rubber powder replacement rate and tapped porosity of mixture.

TABLE 3: Secant slope variation.

\begin{tabular}{|c|c|c|}
\hline \multirow[t]{2}{*}{ Rubber powder replacement rate (\%) } & \multicolumn{2}{|c|}{$\begin{array}{c}\text { Tapped porosity secant } \\
\text { slope }\end{array}$} \\
\hline & Slope & Rate of change (\%) \\
\hline $0-10$ & 0.048 & - \\
\hline $10-30$ & 0.017 & 64.6 \\
\hline $30-50$ & 0.033 & 94.1 \\
\hline $50-70$ & 0.266 & 704.5 \\
\hline $70-90$ & 0.205 & 23.0 \\
\hline
\end{tabular}

compressive resilience modulus decreased by $11.8 \%$. When the replacement rate exceeded $50 \%$, the compressive resilience modulus declined sharply; that of the $90 \%$ replacement rate specimen decreased by $37.1 \%$. This decrease was attributed to the relatively low elastic modulus of the rubber powder, which acted as a soft elastomer in the binder, thus, reducing the overall elastic modulus of the material.

3.1.3. Effect on Plastic Deformation. As the rubber powder replacement rate increased, the cumulative plastic deformation of the mixtures decreased gradually (Figure 4). When the replacement rate reached $30 \%$, large cumulative deformation occurred. The cumulative plasticity of the mixture containing $10 \%$ rubber powder induced deformation of $1.24 \mathrm{~mm}$. When the replacement rate exceeded $30 \%$, the cumulative plastic deformation became small and slowly decreased with the rubber powder replacement rate. The cumulative plastic deformations of the 30 and $90 \%$ replacement rate mixtures were 1.05 and $0.87 \mathrm{~mm}$, respectively. This trend occurred because the rubber powder binder behaved as a soft elastic body; hence, the failure under loading was buffered, and the cumulative plastic deformation of the entire specimen decreased.

Based on the effects of the rubber powder replacement rate on the aggregate structure and deformation, ultrathin

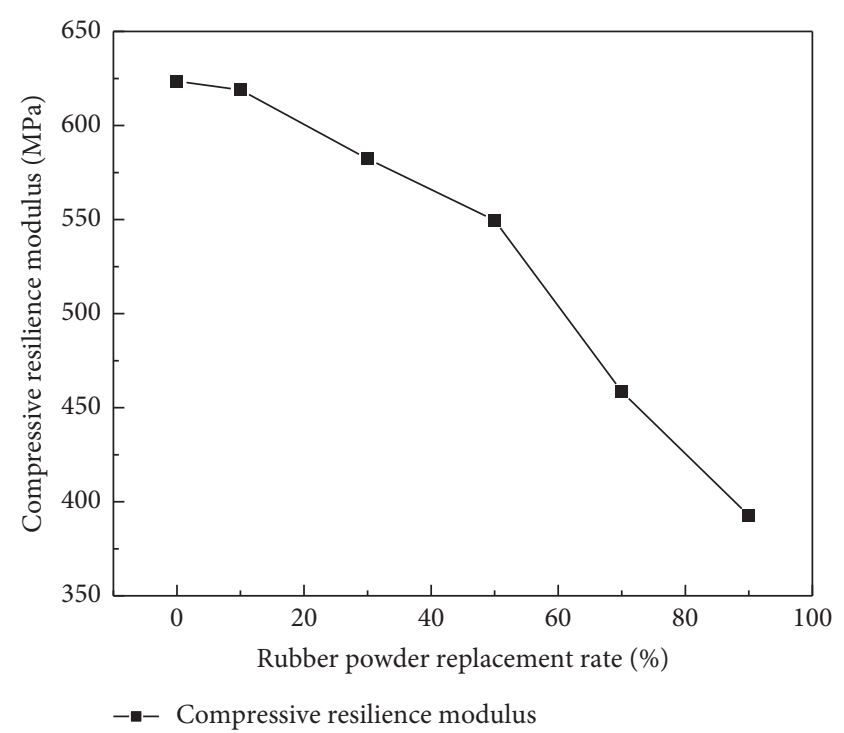

FIgURE 3: Relationship between rubber powder replacement rate and compressive resilience modulus of mixture.

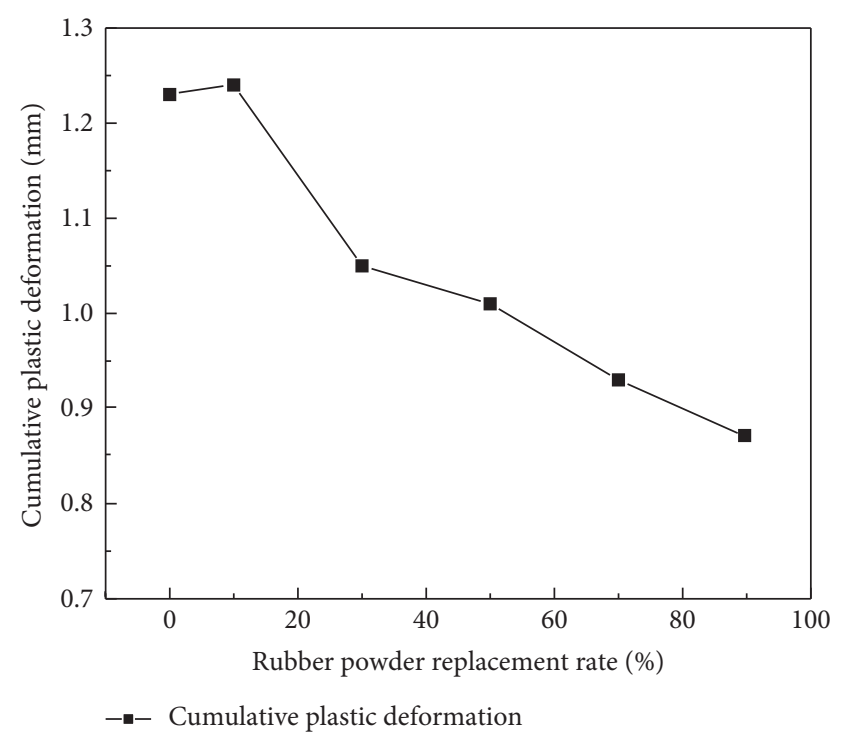

FIGURE 4: Relationship between rubber powder replacement rate and cumulative plastic deformation of mixture.

overlay epoxy-rubber concrete produced with a rubber powder at replacement rates between 30 and 50\% exhibited the best structure and deformation.

\subsection{Effect of Epoxy Resin Dosage on Porosity and Antistripping} Performance of Concrete. A rubber powder replacement rate of $40 \%$ was adopted to prepare the ultrathin overlay epoxyrubber concrete Marshall specimens with epoxy resin dosages of 5.5, 6.0, 6.5, 7.0, and 7.5\%. The specimens were subjected to standard Fort Kentucky tests, and the results are listed in Table 4.

The flying loss of the ultrathin overlay epoxy-rubber concrete containing $40 \%$ rubber powder and $5.5-7.5 \%$ epoxy resin (Table 4) was lower than the value provided in the 
TABle 4: Fort Kentucky test results for concrete with different epoxy resin dosages.

\begin{tabular}{|c|c|c|c|}
\hline Ultrathin coating epoxy-rubber concrete & Epoxy resin dosage $(\%)$ & Porosity (\%) & Flying loss (\%) \\
\hline \multirow{5}{*}{$40 \%$ rubber powder replacement rate } & 5.5 & 7.18 & 10.24 \\
\hline & 6.0 & 5.31 & 4.82 \\
\hline & 6.5 & 4.10 & 2.94 \\
\hline & 7.0 & 2.14 & 1.52 \\
\hline & 7.5 & 1.97 & 1.50 \\
\hline
\end{tabular}

Chinese drainage asphalt mixture specification, which indicated that the ultrathin overlay epoxy-rubber concrete exhibited superior antistripping. The higher the epoxy resin content in concrete, the lower the porosity. This trend was caused by the high viscosity of the epoxy resin binder, which cemented the aggregate and slurry and filled up the aggregate pores. The gap between the slurry and aggregate and the scattering loss of the concrete decreased with decreasing porosity. When the epoxy resin dosage exceeded $7 \%$, the decrease in porosity and flying loss declined. Guo et al. [22] tested the flying loss of SMA mixture with different asphalt contents, and the results showed that the flying loss decreased with increasing asphalt content, which is consistent with the effect of epoxy resin content on the concrete flying loss studied in this paper. Based on economic costs and practical considerations, the optimum epoxy dosage required to satisfy ultrathin finishes was $6.5 \%$. The durability of the mixtures can satisfy the functional requirements of epoxy-rubber concrete pavements.

\subsection{Effect of Rubber Powder Replacement Rate on Mechanical} Properties of Concrete. The rubber powder replacement rates were $0,30,35,40,45$, and $50 \%$. The ultimate strain refers to the strain generated when a material is subjected to its maximum stress or load; the bending-compression ratio is the ratio of the flexural tensile strength of the material to its compressive strength.

The effects of the rubber powder content on the compressive strength and flexural tensile strength of concrete are depicted in Figures 5 and 6, respectively. As the rubber powder content increased to $30-50 \%$, the compressive and flexural tensile strength values of concrete decreased gradually; the compressive strength gradually decreased from 27.1 to $13.0 \mathrm{MPa}$, and the flexural tensile strength gradually decreased from 21.4 to $12.9 \mathrm{MPa}$. However, these values were higher than the compressive strength $(2.5 \mathrm{MPa})$ and flexural tensile strength $(8.5 \mathrm{MPa})$ of the asphalt concrete pavement. Both the ultimate compressive and flexural strains of concrete increased with the rubber powder content. The ultimate compressive strain increased from 5.41 to $11.69 \%$, and the ultimate flexural strain increased from 2.09 to $4.32 \%$. When the replacement rate was lower than $40 \%$, the increase rate was low. The increase rates for the $40-45 \%$ replacement rates increased further, and the ultimate strain increased sharply after the replacement rate exceeded $45 \%$. Therefore, in terms of the mechanical properties of the mixture, the optimum mechanical properties were achieved when the rubber powder replacement rate was lower than $45 \%$. Shao et al. [23] reported the effect of different rubber powders on the mechanical properties of epoxy concrete and concluded

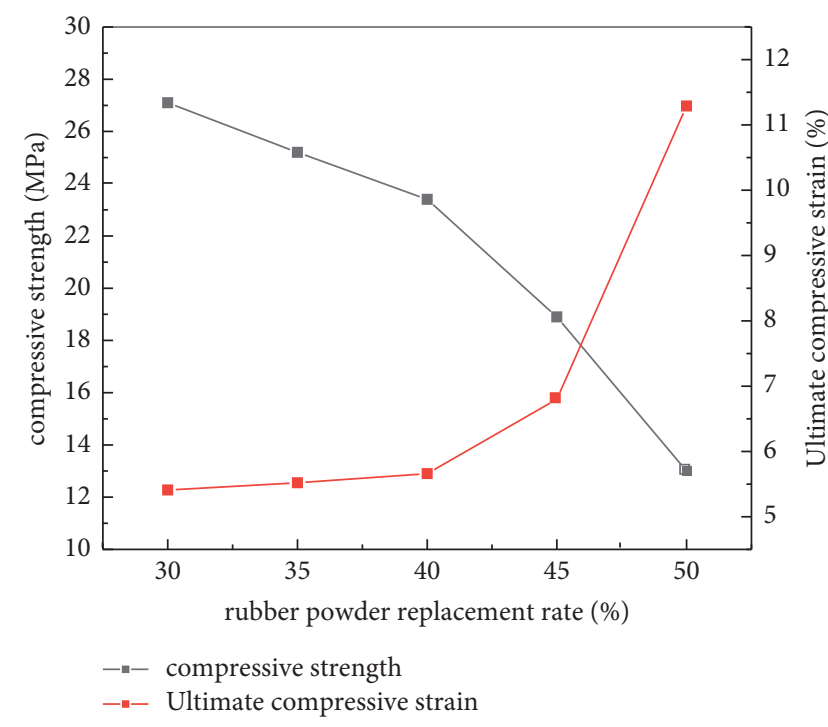

FIGURE 5: Relationship between rubber powder replacement rate and compressive strength of mixture.

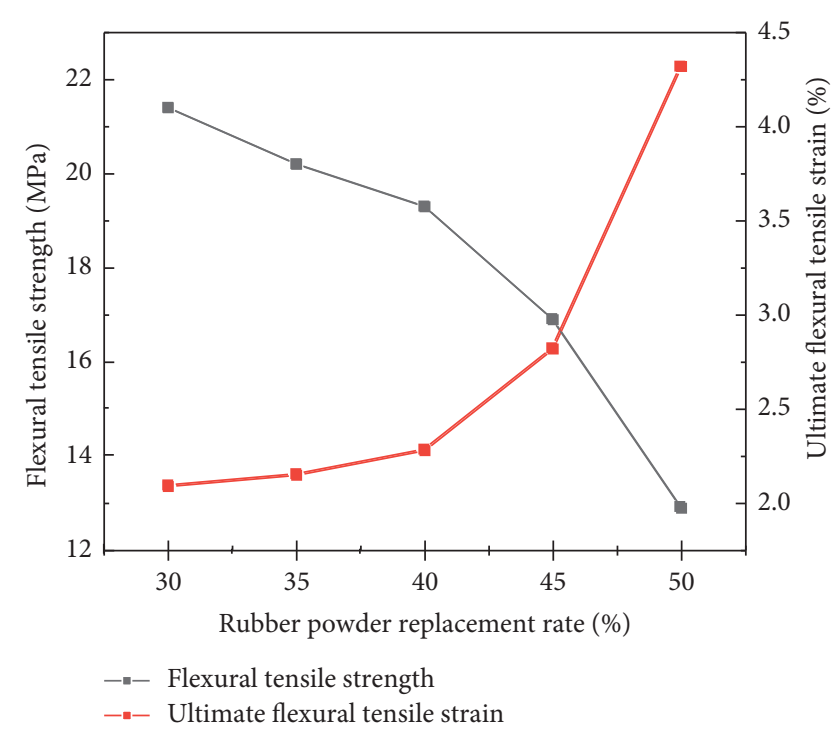

FIGURE 6: Relationship between rubber powder replacement rate and flexural tensile strength of concrete.

that the addition of rubber powder would reduce the strength of epoxy concrete and improve its deformation properties. In the report, the compressive strength, bending tensile strength, and bending strain of epoxy concrete with different rubber contents range from 40 to $67 \mathrm{MPa}, 4.5$ to 6.7 MPa, and 0.1 to $0.2 \%$, respectively, which are quite 
different from the mechanical properties of rubber epoxy concrete in this paper, especially the flexural tensile strength and flexural strain. This is mainly due to the different epoxy resins and curing agents used.

The flexural-compression ratio of the mixture is defined as the ratio of the flexural strength to the compressive strength. This ratio characterizes the flexibility of a material; the higher the flexural-compression ratio of a material, the higher its toughness. The rubber powder content effect on the concrete flexural-compression ratio is depicted in Figure 7 . As the rubber powder content increased (30-50\%), the flexural-compression ratio of concrete increased, indicating enhanced toughness of the ultrathin overlay epoxy-rubber concrete. When the rubber content was lower than $40 \%$, the increase in the flexural-compression ratio declined, but when the content reached $50 \%$, the flexural-compression ratio increased significantly. Therefore, the higher the rubber powder replacement rate, the better the toughness of concrete.

The above results demonstrated that an increase in the rubber powder content increased concrete flexibility but decreased the compressive and flexural tensile strengths. Hence, a rubber powder dosage of $40-45 \%$ is recommended to ensure that the concrete exhibited improved mechanical properties and flexibility.

\subsection{Effect of Rubber Powder Replacement Rate on Road and Noise-Reduction Performance of Concrete}

3.4.1. Effect on High-Temperature and Antiskid Performance. In this study, the rutting stability DS at $60^{\circ} \mathrm{C}$ was used to evaluate the ant rutting ability of ultrathin overlay epoxyrubber concrete. The dynamic stability values for the concrete specimens with different rubber powder contents (Table 5) were significantly higher than those of upper-layer pavements used for heavy traffic (3000 times $/ \mathrm{mm}$ ). These findings indicated that the ultrathin-surface epoxy-rubber concrete exhibited excellent high-temperature performance. The higher the rubber powder replacement rate, the better the high-temperature performance. When the replacement rate was lower than $40 \%$, the dynamic stability increased significantly. After the replacement rate reached $40 \%$, the dynamic stability increased slightly. The pendulum value (British pendulum number, BPN) was used to characterize the macroscopic antiskid performance of concrete. The higher the rubber powder replacement rate, the better the antiskid performance. When the replacement rate was lower than $40 \%$, the pendulum value increased significantly, but the increase in pendulum value dropped when the replacement rate reached $40 \%$. Shu [24] has tested the dynamic stability and pendulum value of epoxy concrete with high rubber powder content, and the ranges of them are 48462-104991 times $/ \mathrm{mm}^{-1}$ and $42-52$, respectively. The results and the variation patterns of these two indexes with rubber powder content were similar to those $t$ in this paper.

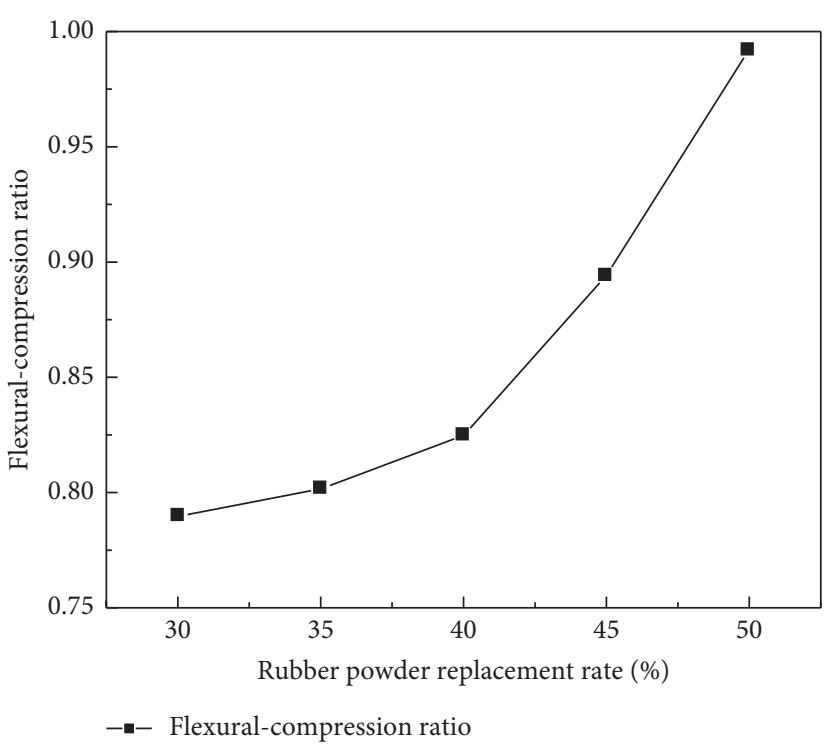

FIgURE 7: Relationship between rubber powder replacement rate and flexural-compression ratio of concrete.

3.4.2. Effect on Noise-Reduction Performance. In this study, the vibration attenuation coefficient was used to characterize the vibration and noise-reduction characteristics of ultrathin overlay epoxy-rubber concrete. As shown in Figure 8, the higher the rubber powder replacement rate, the higher the vibration attenuation coefficient of concrete, indicating that the rubber particles improved the noise-reduction effect on ultrathin overlay epoxy-rubber concrete. In addition, when the replacement rate was lower than $40 \%$, the vibration attenuation coefficient increased significantly. However, when the replacement rate was $40 \%$, the attenuation coefficient attained its maximum value, and subsequently, the rate of increase declined rapidly. Ling et al. studied the effect of rubber particles on the noise-reduction performance of cement concrete and emulsified asphalt mixture [25]. Table 6 shows part of the test results from Ling's study. The addition of rubber particles can improve the noise-reduction performance of cement concrete and asphalt mixture. The vibration attenuation coefficient of rubber epoxy concrete prepared in this paper was between that of cement concrete and emulsified asphalt mixture.

From the analysis of the high-temperature stability, antiskid, shock absorption, and noise resistance performance of the ultrathin-surface epoxy-rubber mixture, it was observed that the road and noise-reduction performance of the concrete were significantly improved when the rubber powder replacement rate was $40-50 \%$. Hence, it is recommended that the rubber powder content should exceed $40 \%$.

In summary, considering the effects of the rubber powder replacement rate on the aggregate structure and deformation, abrasion resistance, mechanical properties, and road performance, and the need to utilize waste rubber powder effectively, the optimum rubber replacement rate was concluded to be $45 \%$. 
TABLE 5: High-temperature and antiskid performance of ultrathin overlay epoxy-rubber concrete.

\begin{tabular}{lccccc}
\hline Rubber powder replacement rate (\%) & 30 & 35 & 40 & 45 & 50 \\
\hline Dynamic stability (times $/ \mathrm{mm})$ & 77814 & 80845 & 94868 & 101250 & 108548 \\
\hline Pendulum (BPN) & 57 & 59 & 63 & 65 & 66 \\
\hline
\end{tabular}

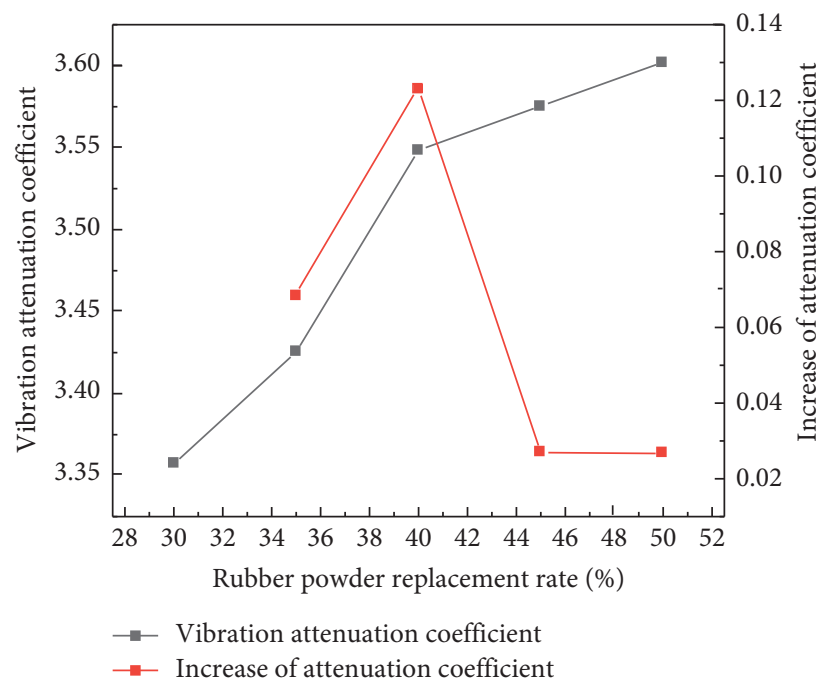

FIGURE 8: Effect of rubber powder replacement rate on vibration characteristics of tire/test piece system.

TABLE 6: Vibration attenuation coefficient of cement concrete and emulsified asphalt mixture with different rubber particle contents [25].

\begin{tabular}{lccccccc}
\hline Concrete type & \multicolumn{3}{c}{ Cement concrete } & \multicolumn{3}{c}{ Emulsified asphalt mixture } \\
\hline Rubber particle content (\%) & 0 & 2 & 3 & 5 & 0 & 2 & 3 \\
Vibration contraction coefficient & 3.039 & 3.532 & 3.756 & 3.775 & 3.442 & 3.545 & 3.863 \\
\hline
\end{tabular}

\section{Conclusion}

(1) Incorporating rubber powder in concrete can reduce the elastic modulus and plastic deformation of the mineral structure, making concrete more suitable for the overlay of flexible pavement. However, when the replacement rate increases to a specific value, it can significantly interfere with the mineral structure and worsen the stability of the concrete mixture. Based on the rubber powder effect on the structure and performance of mineral aggregates, it was preliminarily determined that the optimum replacement rate of rubber powder was $30-50 \%$.

(2) The ultrathin overlay epoxy-rubber concrete exhibited excellent antistripping performance. The porosity increased with the epoxy resin content. A reasonable porosity ensured that the concrete showed a good sealing and durability performance. According to economic requirements, the optimum amount of epoxy resin with $4.17 \%$ porosity was $6.5 \%$.

(3) Within the preliminarily determined replacement rate range for the rubber particles, as the rubber powder replacement rate increased, the flexibility, high-temperature stability, antiskid performance, and shock and noise resistance of the mixture were enhanced. However, the compressive and flexural tensile strengths decreased. From the integrated properties of the ultrathin overlay epoxy-rubber concrete, the best replacement rate of rubber particles was $45 \%$.

The design method for the ultrathin overlay epoxyrubber concrete is as follows: preliminarily determine the range of rubber powder replacement rate, determine the amount of epoxy resin binder, and determine the final replacement rate of rubber powder. This design method is based on the principle of working from part to whole, combined with the characteristics of the part to determine the corresponding constraint index. The design can reflect the performance of ultrathin overlay epoxy-rubber concrete and significantly minimize the effort in designing the epoxyrubber-concrete mix. The proper design is beneficial for promoting the use of epoxy-rubber concrete in road pavements.

\section{Data Availability}

All the data can be found within the article. 


\section{Conflicts of Interest}

The authors declare no conflicts of interest.

\section{Acknowledgments}

The authors are grateful for the financial support provided by the Tibet Science Foundation of China (no. XZ 2019TLG-05).

\section{References}

[1] Z. Liu, S. Luo, X. Quan, X. Wei, X. Yang, and Q. Li, "Laboratory evaluation of performance of porous ultra-thin overlay," Construction and Building Materials, vol. 204, pp. 28-40, 2019.

[2] X. Li, J. Ye, Y. Badjona et al., "Preparation and performance of colored Ultra-Thin overlay for preventive maintenance," Construction and Building Materials, vol. 249, 2020.

[3] N. Suksawang, A. Alsabbagh, A. Shaban, and S. Wtaife, "Using post-cracking strength to determine flexural capacity of ultrathin whitetopping (UTW) pavements," Construction and Building Materials, vol. 240, Article ID 117831, 2020.

[4] J. Wang, Q. Dai, R. Si, and S. Guo, "Investigation of properties and performances of Polyvinyl Alcohol (PVA) fiber-reinforced rubber concrete," Construction and Building Materials, vol. 193, pp. 631-642, 2018.

[5] L. He, H. Cai, Y. Huang et al., "Research on the properties of rubber concrete containing surface-modified rubber powders," Journal of Building Engineering, vol. 35, Article ID 101991, 2020.

[6] M. Valente, M. Sambucci, A. Sibai, and E. Musacchi, "Multiphysics analysis for rubber-cement applications in building and architectural fields: a preliminary analysis," Sustainability, vol. 12, no. 15, Article ID 5993, 2020.

[7] J. Mo, L. Zeng, Y. Liu et al., "Mechanical properties and damping capacity of polypropylene fiber reinforced concrete modified by rubber powder," Construction and Building Materials, vol. 242, Article ID 118111, 2020.

[8] F. Qu, S. Lv, J. Gao, and C. Liu, "Performance and mechanism of asphalt modified by buton-rock asphalt and different types of styrene-butadiene-rubber," Applied Sciences, vol. 10, no. 9, 2020.

[9] S. Poovaneshvaran, M. R. Mohd Hasan, and R. Putra Jaya, "Impacts of recycled crumb rubber powder and natural rubber latex on the modified asphalt rheological behaviour, bonding, and resistance to shear," Construction and Building Materials, vol. 234, 2020.

[10] K.-C. Jung, I.-T. Roh, and S.-H. Chang, "Stress analysis of runway repaired using compliant polymer concretes with consideration of cure shrinkage," Composite Structures, vol. 119, pp. 13-23, 2015.

[11] J. Si, Z. Jia, J. Wang et al., "Comparative analysis of cold-mixed epoxy and epoxy SBS-modified asphalts: curing rheology, thermal, and mechanical properties," Construction and Building Materials, vol. 176, pp. 165-171, 2018.

[12] Y. Liu, J. Zhang, R. Chen, J. Cai, Z. Xi, and H. Xie, "Ethylene vinyl acetate copolymer modified epoxy asphalt binders: phase separation evolution and mechanical properties," Construction and Building Materials, vol. 137, pp. 55-65, 2017.

[13] Q. Xiang and F. Xiao, "Applications of epoxy materials in pavement engineering," Construction and Building Materials, vol. 235, 2020.
[14] N. Ahn, "Influences of metallic polymeric materials on the properties of fresh polyester and acrylic polymer concrete," Journal of Applied Polymer Science, vol. 99, pp. 2337-2343, 2006.

[15] M. Song, R. Liang, J. Deng, and Y. Kang, "Sealed accelerants facilitate epoxy asphalt concretes opening to traffic quickly," Construction and Building Materials, vol. 147, pp. 1-8, 2017.

[16] R. A. Pearson and A. F. Yee, "Toughening mechanisms in elastomer-modified epoxies," Journal of Materials Science, vol. 21, no. 7, pp. 2475-2488, 1986.

[17] W. Shen, L. Shan, T. Zhang, H. Ma, Z. Cai, and H. Shi, "Investigation on polymer-rubber aggregate modified porous concrete," Construction and Building Materials, vol. 38, pp. 667-674, 2013.

[18] R.-M. Diaconescu, M. Barbuta, and M. Harja, "Prediction of properties of polymer concrete composite with tire rubber using neural networks," Materials Science and Engineering: $B$, vol. 178, no. 19, pp. 1259-1267, 2013.

[19] I.-T. Roh, K.-C. Jung, S.-H. Chang, and Y.-H. Cho, "Characterization of compliant polymer concretes for rapid repair of runways," Construction and Building Materials, vol. 78, pp. 77-84, 2015.

[20] J. Wang, Q. Dai, S. Guo, and R. Si, "Mechanical and durability performance evaluation of crumb rubber-modified epoxy polymer concrete overlays," Construction and Building Materials, vol. 203, pp. 469-480, 2019.

[21] M. Rangelov, S. Nassiri, Z. Chen, M. Russell, and J. Uhlmeyer, "Quality evaluation tests for pervious concrete pavements' placement," International Journal of Pavement Research and Technology, vol. 10, no. 3, pp. 245-253, 2017.

[22] N. Guo, W. Li, H. Zhao, and Y.-Q. Tan, "Determination method of optimum asphalt content of SMA mixture considering homogeneity," Journal of Dalian Maritime University, vol. 43, no. 2, pp. 115-122, 2017.

[23] J. Shao, H. Zhu, X. Zuo et al., "Effect of waste rubber particles on the mechanical performance and deformation properties of epoxy concrete for repair," Construction and Building Materials, vol. 241, Article ID 118008, 2020.

[24] X. Shu, "Mechanical properties and pavement performance of modified epoxy concrete with high content of waste rubber," Journal of Beijing University of Technology, vol. 44, no. 10, pp. 1314-1320, 2018.

[25] T. Lin, "Influence of rubber particles on micro-surfacing performance and its noise-reduction effect," Journal of Traffic and Transportation Engineering, vol. 11, no. 5, pp. 1-5, 2011. 